\title{
Shoot Blight on Chinese Fir (Cunninghamia lanceolata) is Caused by Bipolaris oryzae
}

Lin Huang, ${ }^{\dagger}$ Ya-Nan Zhu, and Ji-Yun Yang, College of Forestry and Co-Innovation Center for Sustainable Forestry in Southern China, Nanjing Forestry University, Nanjing, Jiangsu 210037, China; De-Wei Li, The Connecticut Agricultural Experiment Station Valley Laboratory, Windsor 06095; and Co-Innovation Center for Sustainable Forestry in Southern China, Nanjing Forestry University; Yong Li, Yangkou State Forest Farm, Nanping, Fujian 353211, China; and Li-Ming Bian and Jian-Ren Ye, ${ }^{\dagger}$ College of Forestry and Co-Innovation Center for Sustainable Forestry in Southern China, Nanjing Forestry University

\begin{abstract}
Chinese fir (Cunninghamia lanceolata) is a significant timber species that has been broadly cultivated in southern China. A shoot blight disease on Chinese fir seedlings was discovered in Fujian, China and a fungus was then consistently associated with the symptoms. This fungus was determined to be causing this disease, among others by fulfilling Koch's postulates. Based on morphological characteristics and multilocus phylogenetic analyses with the sequences of the internal transcribed spacer, partial glyceraldehyde-3-phosphate dehydrogenase gene, partial translation elongation factor $1-\alpha$ gene, and partial 28 S large subunit ribosomal RNA gene,

the fungus was identified as Bipolaris oryzae. These characteristics and phylogenetic analyses clearly support that this pathogen is different from $B$. sacchari, which was, until now, considered to be the causal agent of a similar blight on Chinese fir in Guangdong, China. The fungus was also shown to be strongly pathogenic to rice, one of the most susceptible hosts to $B$. oryzae. Crop rotation involving rice is often carried out with Chinese fir in southern China, a practice that most likely increases the risk of shoot blight on $C$. lanceolata. To our knowledge, shoot blight caused by $B$. oryzae is reported for the first time in a gymnosperm species.
\end{abstract}

The ascomycete genus Bipolaris includes significant phytopathogens with a worldwide distribution. Species in this genus cause leaf spots, leaf blights, melting outs, root rots, foot rots, and other diseases, primarily in the Poaceae family, which includes maize, rice, sorghum, and wheat, and on other hosts (Berbee et al. 1999; Ellis 1971; Sivanesan 1987; Verma et al. 2002). In addition to hosts in the Poaceae family, species of Bipolaris have been reported on at least 60 other plant genera in nongrass families as either saprobes or pathogens (Ellis 1971; Manamgoda et al. 2011; Sanahuja et al. 2017; Sivanesan 1987). Like most fungi, species of Bipolaris are difficult to identify based on morphology alone (Sivanesan 1987). Considerable progress has been made in defining species in Bipolaris. Manamgoda et al. (2014) recognized 47 species in Bipolaris based on morphological features and phylogenetic analysis using combined alignment of internal transcribed spacer (ITS), partial glyceraldehyde-3-phosphate dehydrogenase gene $(G P D H)$, and partial translation elongation factor $1-\alpha$ gene $(T E F-1 \alpha)$ sequences. However, lack of sequences from ex-type or authenticated cultures in public databases is a major factor hindering the correct identification of Bipolaris spp. using molecular methods (Cai et al. 2011; Manamgoda et al. 2012).

Rice brown spot caused by Bipolaris oryzae is one of the most damaging diseases on rice worldwide, which reduces the yield by around 16 to 43\% (Jatoi et al. 2016). This disease has led to historical damage to rice crops, causing the starvation of large human populations (Manamgoda et al. 2014). Considerable variation in conidial morphology and genetic characteristics has been reported within this species (Cholil and de Hoog 1982; Subramanian and Bhat 1978). The variation is reflected by its broad host range. Hosts of $B$. oryzae include not only species of the Poaceae

${ }^{\dagger}$ Corresponding authors: L. Huang; E-mail: lhuang@njfu.edu.cn; and J.-R. Ye; E-mail: jrye@ njfu.edu.cn

*The $\boldsymbol{e}$-Xtra logo stands for "electronic extra" and indicates that four supplementary figures are published online.

Accepted for publication 3 October 2017.

C) 2018 The American Phytopathological Society family such as Oryza sativa, Panicum maximum, and Zizania latifolia but also Boraginaceae trees such as Cordia trichotoma (Manamgoda et al. 2014).

Chinese fir (Cunninghamia lanceolata (Lamb.) Hook, family Cupressaceae) is an important conifer species for lumber production in China, where it has been cultivated for over 3,000 years (Shi et al. 2010). Chinese fir is cultivated in the areas between latitude 20 and $34^{\circ} \mathrm{N}$ and from longitude 100 to $120^{\circ} \mathrm{E}$ in China, and contributes about $40 \%$ of timber supply in southern China (Zheng et al. 2016). However, Chinese fir is frequently decimated by various pests (Lan et al. 2015). Shoot blight is one of the fungal diseases affecting Chinese fir. Wang et al. (1995) reported that B. sacchari (E. J. Butler) Shoemaker appears to be the main pathogen causing shoot blight disease on Chinese fir in Guangdong, China.

The objectives of this research are to better characterize the causal agent of shoot blight disease on C. lanceolata in Fujian, China, and to identify the pathogen using both morphological and multilocus phylogenetic approaches.

\section{Materials and Methods}

Plants materials. Eleven-month-old seedlings of $C$. lanceolata obtained from aseptic tissue culture were supplied by Yangkou State Forest Farm, Fujian Province, China, and used for pathogenicity tests. Seeds of susceptible rice variety CO39 and maize variety Denghai11 were sown in the soil matrix (Pindstrup, Denmark) and grown in an incubator at $25^{\circ} \mathrm{C}$ with a 12 -h photoperiod. For pathogenicity tests, 13-day-old rice and 15-day-old maize plants were used.

Isolation of the pathogen. The shoot blight disease was discovered in 1-year-old seedlings of Chinese fir in October 2016 in Yangkou State Forest Farm $\left(26^{\circ} 49^{\prime} 18^{\prime \prime} \mathrm{N}, 117^{\circ} 53^{\prime} 30^{\prime \prime} \mathrm{E}\right)$, Fujian, China. In order to isolate the fungus, infected shoots and needles were collected and surface sterilized using the method of Huang et al. (2016). Lesion margins were cut into pieces $(0.2$ by $0.2 \mathrm{~cm})$ and placed on $2 \%$ potato dextrose agar (PDA) Petri plates. The plates were incubated at $25^{\circ} \mathrm{C}$ for 7 days. Fungal isolates were purified with the monosporic isolation method described by $\mathrm{Li}$ et al. (2007). Single-spore isolates were maintained on PDA medium plates.

Pathogenicity tests. To stimulate sporulation of fungal isolates, 7-day-old cultures were exposed to a fluorescent cycle of $12 \mathrm{~h}$ of light 
and $12 \mathrm{~h}$ of darkness at $25^{\circ} \mathrm{C}$. Four days later, conidia were collected and suspended in sterile distilled water, and the final concentration was adjusted to $1 \times 10^{5}$ spores $\mathrm{ml}^{-1}$. Unwounded seedlings each of Chinese fir, rice leaves, and maize leaves were inoculated by spraying with the conidial suspension until leaves were covered with fine droplets. At the same time, the shoots of Chinese fir were slightly wounded by a sterile needle and inoculated with $5 \mu \mathrm{l}$ of the conidial suspension. Plants treated with the sterile distilled water were employed as controls. The inoculated plants were placed in the dark for $24 \mathrm{~h}$. Then, these plants were kept in an incubator at $25^{\circ} \mathrm{C}$ under a 12 -h photoperiod. The experiment was repeated twice and there were three replicates for each treatment.

In order to investigate the pathogenicity of the fungal isolates on Chinese fir in the field, new shoots were collected. A conidial suspension was prepared as described above. The conidial suspension $(10 \mu \mathrm{l})$ was inoculated on the apical portion of the shoots of Chinese fir. After inoculation, the shoots were placed in 9-cm Petri dishes containing a piece of wet paper and placed in darkness for $24 \mathrm{~h}$, then incubated under a 12 -h photoperiod at $25^{\circ} \mathrm{C}$. Shoots treated with sterile distilled water were used as controls. Three shoots were inoculated for each treatment, and the experiment was replicated three times.

In order to complete Koch's postulates, the fungus was reisolated from the lesion margins as described above. Colony, conidium, and conidiophore characteristics of the reisolated fungus were observed to confirm the identity of the fungus inoculated. The experiment was conducted three times, with three replicates per treatment for each host.
Morphological analysis. Three plates of either PDA, complete medium (CM), corn meal agar (CMA), or V8 vegetable juice medium (V8) were used to assess the colony growth rates of fungal isolates. Mycelial blocks (5 $\mathrm{mm}$ in diameter) of the fungus taken from PDA were inoculated in the center of the plates that were placed in an inoculator at $25^{\circ} \mathrm{C}$. Colony diameters were measured at $1,3,5$, and 7 days postinoculation (dpi), and the average growth rates were calculated.

Colony characteristics and pigment production on media plates at $25^{\circ} \mathrm{C}$ were examined at $7 \mathrm{dpi}$. Conidiophores and conidia were measured following the procedure of Manamgoda et al. (2014). In order to observe conidial germination, $20 \mu \mathrm{l}$ of the conidial suspensions at the concentration of $1 \times 10^{5}$ spores $\mathrm{ml}^{-1}$ were added onto the glass slides and incubated at $25^{\circ} \mathrm{C}$. Conidial germination and the length of germ tubes were observed and measured at 1, 2, 4, and $8 \mathrm{~h}$. At least 30 measurements were made for each fungal structure with a ZEISS Axio Imager A2m microscope (ZEISS) using differential interference contrast. In order to observe fungal structures on the surface of seedlings, shoots and leaves were collected and prepared according to Zhou et al. (2016). Photomicrographs were taken under a Quanta 200 environmental scanning electron microscope (FEI).

Molecular identification and phylogenetic analysis. Genomic DNA was extracted following the method of Damm et al. (2008). ITS, GPDH, TEF- $1 \alpha$, and partial $28 \mathrm{~S}$ large subunit ribosomal RNA gene $(L S U)$ were amplified and sequenced with the primer pairs ITS-1/ITS-4 (White et al. 1990), gpd1/gpd2 (Manamgoda et al. 2012), EF983/2218R

Table 1. GenBank accession numbers of strains used for the phylogenetic analysis in this study

\begin{tabular}{|c|c|c|c|c|c|}
\hline \multirow[b]{2}{*}{ Species } & \multirow[b]{2}{*}{ Strain number } & \multicolumn{4}{|c|}{ GenBank accession number ${ }^{a}$} \\
\hline & & ITS & GPDH & $E F 1-\alpha$ & $L S U$ \\
\hline Bipolaris bicolor & CBS 690.96 & KJ909762 & KM042893 & KM093776 & KM243287 \\
\hline B. chloridis & CBS 242.77 & JN192372 & JN600961 & $\ldots$ & $\ldots$ \\
\hline B. clavate & BRIP 12530 & KJ415524 & KJ415422 & KJ415471 & KJ415477 \\
\hline B. coffeana & BRIP 14845 & KJ415525 & KJ415421 & KJ415470 & KJ415478 \\
\hline B. crotonis & BRIP 14838 & KJ415526 & KJ415420 & KJ415469 & KJ415479 \\
\hline B. cynodontis & CBS 109894 & KJ909767 & KM034838 & KM093782 & KM243288 \\
\hline B. drechsleri & FIP 373 & KF500531 & KF500534 & KM093759 & $\cdots$ \\
\hline B. eleusines & CBS 274.91 & KJ909768 & KM034820 & KM093758 & KM243289 \\
\hline B. gossypina & BRIP 14840 & KJ415528 & KJ415418 & KJ415467 & KJ415481 \\
\hline B. heveae & CBS 241.92 & KJ909763 & AY004811 & KM093791 & KM243294 \\
\hline B. heliconiae & BRIP 17189 & KJ415530 & KJ415417 & KJ415465 & KJ415483 \\
\hline B. maydis & AR 5182 & KM230388 & KM034844 & KM093792 & $\ldots$ \\
\hline B. microlaenae & BRIP 15613 & JN192378 & JN600973 & JN601017 & JN600995 \\
\hline \multirow[t]{2}{*}{ B. microstegii } & AR 4840 & JX089579 & JX089575 & KM093756 & JX100808 \\
\hline & AR 5192 & KM230391 & KM034819 & KM093757 & $\ldots$ \\
\hline B. multiformis & CBS 480.74 & KJ909771 & KM034827 & KM093768 & KM243282 \\
\hline \multirow[t]{10}{*}{ B. oryzae } & SMYK1 & MF185132 & MF431722 & MF431724 & MF431723 \\
\hline & AR 5204 & KM230393 & KM042895 & KM093787 & KM243277 \\
\hline & MAFF 235499 & KJ922383 & KM042897 & KM093789 & $\ldots$ \\
\hline & MFLUCC 10-0694 & JX256413 & JX276428 & JX266582 & $\ldots$ \\
\hline & MFLUCC 10-0715 & JX256416 & JX276430 & JX266585 & JX256384 \\
\hline & MFLUCC 10-0733 & JX256417 & JX276431 & JX266586 & JX256385 \\
\hline & MFLUCC 13-0511 & KF688965 & KF688971 & KF688977 & $\ldots$ \\
\hline & MFLUCC 13-0512 & KF688966 & KF688972 & KF688978 & $\ldots$ \\
\hline & MFLUCC 13-0513 & KF688967 & KF688973 & KF688979 & $\cdots$ \\
\hline & MFLUCC 13-0514 & KF688968 & KF688974 & KF688980 & $\ldots$ \\
\hline B. panici-miliacei & CBS 199.29 & KJ909773 & KM042896 & KM093788 & KM243281 \\
\hline B. peregianensis & BRIP 12790 & JN601034 & JN600977 & JN601022 & JN601000 \\
\hline B. pluriseptata & BRIP 14839 & KJ415532 & KJ415414 & KJ415461 & KJ415486 \\
\hline B. sacchari & ICMP 6227 & KJ922386 & KM034842 & KM093785 & $\ldots$ \\
\hline B. secalis & BRIP 14453 & KJ415537 & KJ415409 & KJ415455 & KJ415492 \\
\hline \multirow[t]{2}{*}{ B. sorokiniana } & CBS 120.24 & KJ909776 & KM034821 & KM093762 & KM243278 \\
\hline & MAFF 235500 & KJ909789 & KM034823 & KM093764 & $\ldots$ \\
\hline B. victoriae & CBS 327.64 & KJ909778 & KM034811 & KM093748 & KM243271 \\
\hline B. zeae & AR 5181 & KM230394 & KM034817 & KM093754 & $\ldots$ \\
\hline B. zeicola & AR 5166 & KJ909788 & KM034813 & KM093750 & $\ldots$ \\
\hline Curvularia lunata & CBS 730-96 & JX256429 & JX276441 & JX266596 & JX256396 \\
\hline
\end{tabular}

\footnotetext{
a Internal transcribed spacer (ITS), partial glyceraldehyde-3-phosphate dehydrogenase gene (GPDH), partial translation elongation factor 1- $\alpha$ gene $(T E F-1 \alpha)$, and
} partial 28S large subunit ribosomal RNA gene $(L S U)$. 
(Schoch et al. 2009), and LR5/LROR (Schoch et al. 2009). Polymerase chain reaction (PCR) was carried out in an Eppendorf Nexus Thermal Cycler (Eppendorf) in a total volume of $50 \mu$ l using the method of Huang et al. (2016). Amplicons were sequenced by the Sangni Biotechnology Company. DNA sequences obtained were aligned and edited using the Molecular Evolutionary Genetic Analysis (MEGA 7.0) with Clustal W (Thompson et al. 1994). All sequences generated in the present study have been blasted in GenBank. Sequences with high similarities were selected for phylogenetic analysis (Table 1).

The phylogenetic analysis was conducted with each gene or region and the concatenated sequences of ITS, GPDH, TEF1- $\alpha$, and $L S U$ using MEGA 7.0 software (Kumar et al. 2016). Other Bipolaris sequences were obtained from GenBank for the analysis. Curvularia lunata was employed as an out-group. The multilocus phylogenetic tree was built using neighbor-joining analysis (the Tamura three-parameter model) with the gaps pairwise deletion option. The tree was drawn with branch lengths measured in the number of substitutions per site. The interior-branch test was performed using 1,000 bootstrap replications to evaluate the relative stability of the branches.

\section{Results}

Symptoms of shoot blight disease on Cunninghamia lanceolata in nature. The disease mainly infected the shoots of Chinese fir and the infection rate of the seedlings reached $82 \%$ (Fig. 1A). Some white resin was visible on infected shoots (Fig. 1B). These shoots, and the leaves in particular, appeared brown to brownish red (Fig. 1C). On dead shoots, abundant mycelium was observed (Fig. 1D). A large number of conidia and conidiophores developed on the surface of the leaves (Fig. 1E). Scanning electron micrographs also confirmed the presence of mycelium, conidia, and conidiophores on the surface of infected shoots (Fig. 1F).

Pathogenicity tests using fungal isolate SMYK1 on Chinese fir. Seven fungal isolates were obtained from the infected shoots. Because these isolates shared nearly identical colony characteristics and conidia morphological features, an isolate was randomly selected, and named SMYK1, for the pathogenicity assessment and morphological study.

In order to fulfill Koch's postulates, conidia were sprayed on healthy, aseptic tissue culture of seedlings of Cunninghamia lanceolata. Seven days after inoculation, blight symptoms occurred on the shoots (Fig. 2A). At the early stage of symptom development, there were irregular, brown spots on the surface of the leaves; later, white to gray centers were formed on the brown lesions (Fig. 2B). When the wounded shoots were inoculated with conidial suspension, similar symptoms were observed at $7 \mathrm{dpi}$ (Fig. 2C). At the same time, abundant mycelium appeared on the infected leaves and stems (Fig. 2D). After exposing the diseased tissues to a 12-h fluorescent photoperiod for 3 days, conidiophores and conidia were observed (Fig. 2E). Control seedlings remained healthy and did not yield any microorganisms. When shoots of Chinese fir collected from the field were inoculated by the fungus, typical symptoms were observed by 9 dpi whereas no symptoms developed on shoots treated with water (Fig. 3). These symptoms were similar to the typical symptoms of this disease in nature. In addition to morphological features of colonies, aerial mycelia
A
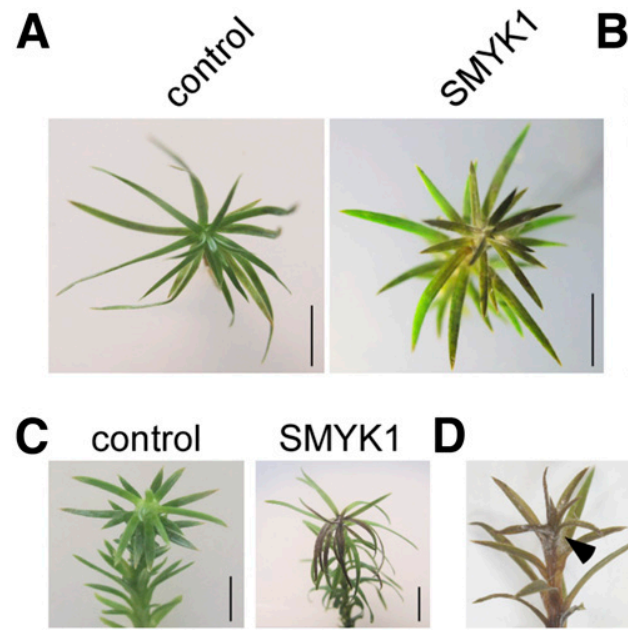

SMYK1 D
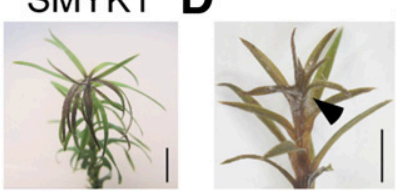

E

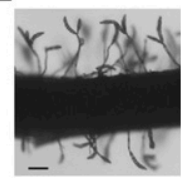

Fig. 2. Pathogenicity of fungal isolate SMYK1 on seedlings of Chinese fir obtained by tissue culture. A, Unwounded seedlings were inoculated with conidia of SMYK1. B, Disease spots formed at an early stage of symptom development. C, Wounded seedlings were inoculated with conidia of SMYK1. D, Diseased shoot of Cunninghamia lanceolata. Arrowhead indicates mycelium on the diseased shoot. Bars $(A$ to $D)=0.5 \mathrm{~cm}$. E, Conidia and conidiophores formed on the diseased leaves. $\operatorname{Bar}(E)=100 \mu \mathrm{m}$.

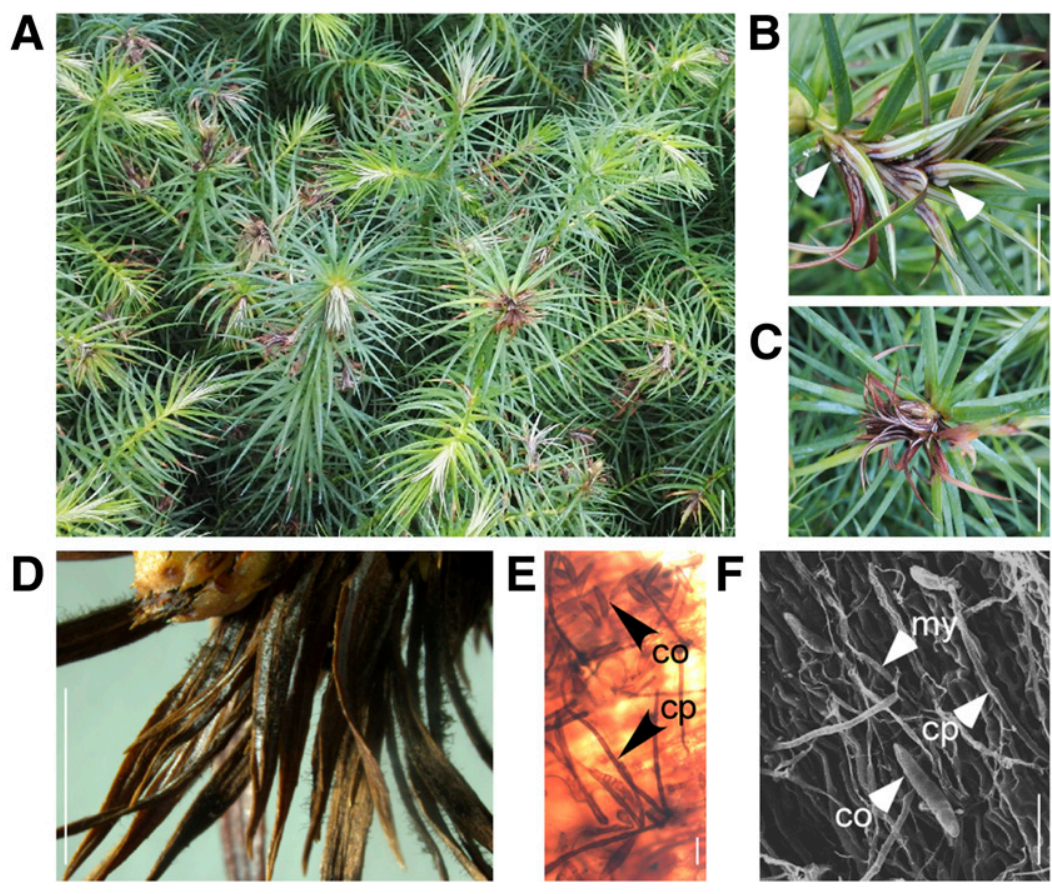

Fig. 1. Symptoms of shoot blight disease on Cunninghamia lanceolata. A, Diseased shoots in the field. B and C, Diseased shoots of $C$. lanceolata. Arrows indicate the white oozed resin on the shoot. D, Mycelium on the infected shoot. Bars $(A$ to $D)=2 \mathrm{~cm}$. E, Conidia and conidiophores on the infected shoot. F, Scanning electron photomicrograph of fungal mycelium, conidia and conidiophores on the infected shoot; my, co, and $\mathrm{cp}$ indicate mycelium, conidia, and conidiophores, respectively. Bars (E and $\mathrm{F})=100 \mu \mathrm{m}$. 
and conidia of the fungus reisolated from the margin of necrotic areas after the appearance of symptoms were similar to the initial inoculated strain SMYK1. No fungal isolate was reisolated from the controls. These results indicated that SMYK1 was the pathogen of shoot blight on $C$. lanceolata. The living culture of SMYK1 has been deposited in the China Center for Type Culture Collection (CCTCC AF 2017004) at Wuhan University, Wuhan City, Hubei Province, China.

Morphological characteristics of SMYK1. Colonies grown on PDA were irregularly round, and mycelial growth rate was $1.11 \mathrm{~cm} /$ day, on average (Fig. 4A; Supplementary Fig. S1). Aerial mycelium was dense, felted, and pale gray at an early stage (Fig. 4A). With age, the color darkened and finally became grayish green. The colonies produced black pigments (Fig. 4A and B). On CM, CMA, and V8 plates, the colonies showed similar color changes. The colonies showed slower growth rates on CMA.

When the colonies growing on PDA, CM, CMA, and V8 plates were exposed to a 12-h fluorescent photoperiod for 3 days, abundant conidia and conidiophores were observed (Fig. 4B and C). Conidiophores were solitary or in groups, brown, less branched, multiseptate, and flexuous, with upper parts geniculate (Figs. 1E, 4C, and 5A). The average length of conidiophores was $190.9 \pm 38.5 \mu \mathrm{m}$ and the average width was $8.1 \pm 1.2 \mu \mathrm{m}$. Conidia were usually curved, rarely straight, fusiform, navicular, obclavate or nearly cylindrical, colorless when immature, turning brown when mature, oblong, spindle-shaped, cylindrical, rarely straight, and usually bent to one side (Fig. 5B). Most conidia were 7- to 9-distoseptate (Fig. 5C). Conidial size varied from 76.8 to 117.8 by 13.4 to $18.4 \mu \mathrm{m}$, with a mean \pm standard deviation of $97.3 \pm 20.5$ by $15.9 \pm 2.5 \mu \mathrm{m}(n=30)$.

Conidia germinated from both ends. Most conidia germinated within $1 \mathrm{~h}$ in double-distilled $\mathrm{H}_{2} \mathrm{O}$ (Supplementary Fig. S2). At $4 \mathrm{~h}$, conidium germination rate was up to $97.2 \%$. At $1,2,3$, and $4 \mathrm{~h}$, the average length of the germ tubes was $43.4 \pm 36.1,110.7 \pm$ 56.3, $169.7 \pm 90.8$, and $180.6 \pm 131.7 \mu \mathrm{m}$, respectively $(n>20)$. The primary germ tubes were colorless. These morphological characteristics matched the epitype culture selected for $B$. oryzae by Manamgoda et al. (2014).

Molecular characterizations of the fungal pathogen. The ITS, $G P D H, E F 1-\alpha$, and $L S U$ sequences obtained from B. oryzae SMYK1 were deposited in GenBank (accession numbers MF185132, MF431722, MF431724, and MF431723, respectively). The ITS sequence showed $99 \%$ identity, with $100 \%$ Query Cover, to many B. oryzae strains deposited in GenBank (e.g., KU499535). The GPDH sequence matched 99\% with the B. oryzae strain MFLUCC 13-0511 (KF688971.1). The TEF1- $\alpha$ sequence showed $100 \%$ identity to the $B$. oryzae strain MFLUCC 13-0511 (KF688977.1). The $L S U$ sequence showed 99\% similarity with B. oryzae strain B34 (KM111240.1).

A phylogenetic tree calculated from $G P D H$ sequences showed that SMYK1 is most closely related to $B$. oryzae, and grouped together with $B$. oryzae isolate MFLUCC $10-0733$ with a $64 \%$ bootstrap value support (Fig. 6). This group clustered with other five B. oryzae isolates with a $75 \%$ bootstrap support (Fig. 6). A phylogenetic tree calculated from concatenated sequences of the ITS and GPDH gene also showed that SMYK1 was clustered with six B. oryzae strains with $74 \%$ bootstrap support (Supplementary Fig. S3). Phylogenetic relationships analyzed with concatenated sequences of ITS, GPDH, and TEF1- $\alpha$ also supported the finding that SMYK1 was clustered with seven B. oryzae strains with $82 \%$ bootstrap support (Supplementary Fig. S4). Phylogenetic analysis using the concatenated sequences of ITS, GPDH, TEF1- $\alpha$, and $L S U$ also illustrated that SMYK1 and authentic strains of B. oryzae were monophyletic, supported with a significantly higher bootstrap value (Fig. 7). All these results showed that SMYK1 is most likely B. oryzae.

Pathogenicity of SMYK1 to rice and maize. According to the morphological and molecular characteristics, SMYK1 was identified as $B$. oryzae. Pathogenicity tests of SMYK1 on rice showed that brown spots occurred at $3 \mathrm{dpi}$ (Fig. 8A). These spots enlarged and amalgamated to form larger chlorotic to necrotic spots at 4 to 5 dpi. At 6 dpi, these spots further developed and formed lesions. There were no symptoms on the negative controls (Fig. 8A). Conidia were produced on the spots when the diseased leaves were exposed to a 12-h fluorescent photoperiod (Fig. 8B). When conidia were sprayed on the maize leaves, gray spots were formed. These spots failed to enlarge to produce the typical lesions. No spots occurred on the leaves of the controls (Fig. 8C). After the appearance of symptoms on rice and maize leaves, the fungus was reisolated from the transitional region between infected and healthy areas. Morphological characteristics of colonies, aerial mycelia, and conidia were similar to the initial inoculated strain SMYK1. No fungi were isolated from the healthy leaves of rice and maize. These results strongly suggested that SMYK1 is the sole cause of shoot blight observed on Chinese fir in the present study, and this strain also appeared strongly pathogenic on rice and weakly pathogenic on maize.

\section{Discussion}

In this study, a shoot blight was discovered on young seedlings of $C$. lanceolata in Fujian, China and determined to be caused by B. oryzae. Wang et al. (1995) reported that B. sacchari was the causal agent of a similar blight on $C$. lanceolata in Guangdong, China. However, the morphological characteristics of $B$. sacchari are different from those of $B$. oryzae. For example, the average conidial size of $B$. sacchari is $74 \pm$ 19 by $13 \pm 1 \mu \mathrm{m}$ (Manamgoda et al. 2014), which is significantly smaller than that reported in the present study for SMYK1. Leaf spot symptoms of $B$. sacchari were initially small, red, elongating parallel to the midvein, and then producing eye spots with a light yellow center and red halo. This is also different from the symptoms induced by SMYK1, which formed brown spots on leaves, having later white to gray centers. Because the specimen, culture, and sequence accession number of the
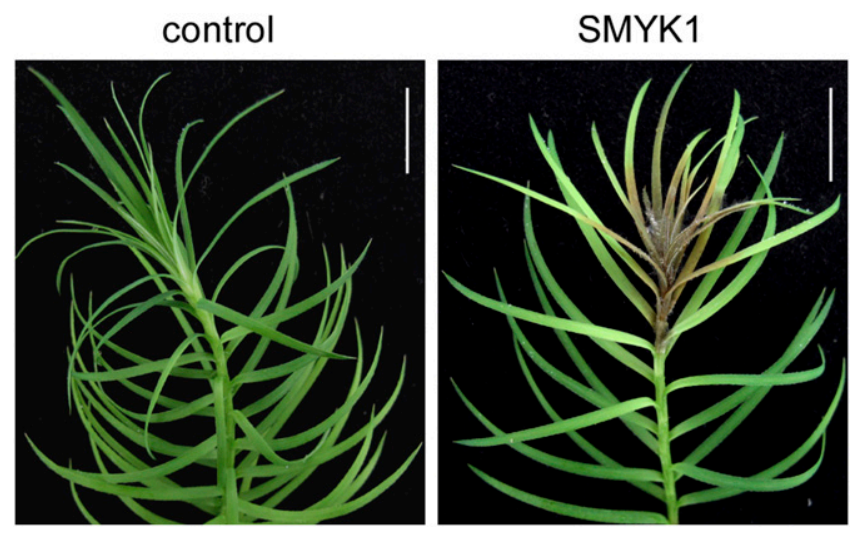

Fig. 3. Pathogenicity of fungal isolate SMYK1 on detached shoots of Chinese fir. Bars= $2 \mathrm{~cm}$.
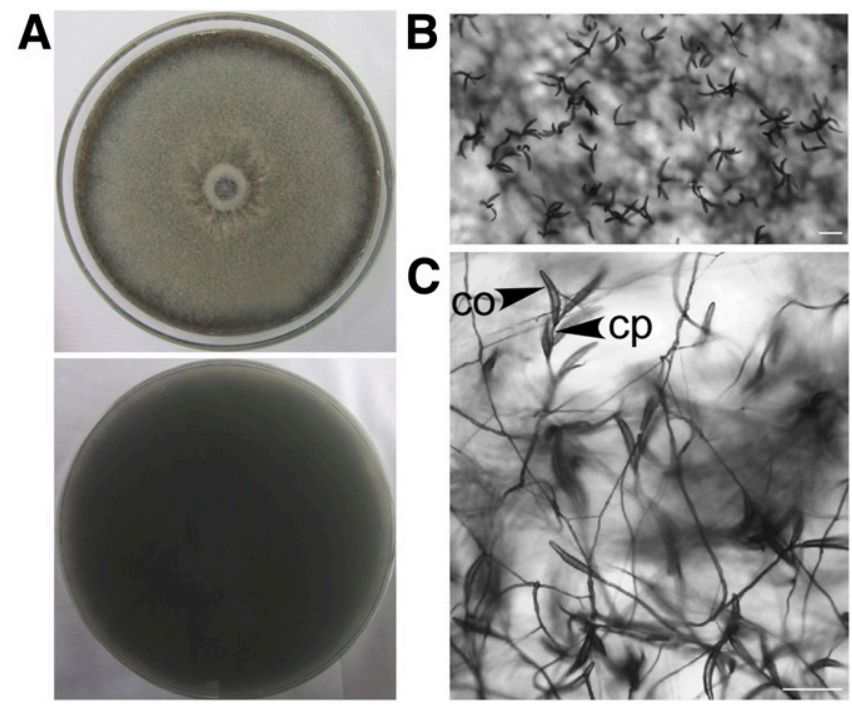

Fig. 4. Colony morphology and conidia development of SMYK1 on the potato dextrose agar medium plates. A, Top and reverse view of a colony. B, Numerous dark conidia were obvious and $\mathbf{C}$, at higher magnification, conidia (Co) were seen attached to their conidiophores (cp). Bars $=100 \mu \mathrm{m}$. 
fungus of Wang et al. (1995) is not available, the similarity between their pathogen and SMYK1 cannot be verified or determined. However, our phylogenetic analysis using sequences of GPDH (Fig. 6); the concatenated sequences of ITS and GPDH; and ITS, GPDH, and TEF- $1 \alpha$ showed that $B$. sacchari and B. oryzae, including strain SMYK1, fall into two different clades. Thus, these results indicate for the first time that this shoot blight is actually caused by $B$. oryzae on Chinese fir.

In terms of molecular characterization of eukaryotic microbes, the ITS sequence is considered an important region often employed for species identification (Johannesson and Stenlid 1999; Malan et al. 2011). For several fungi, the ITS region has been proposed as a universal DNA marker (Schoch et al. 2012); however, for some large genera of fungi such as Alternaria, Bipolaris, and Colletotrichum, their species cannot be efficiently distinguished using solely ITS sequence data (Brun et al. 2013; Manamgoda et al. 2014; Weir et al. 2012). Consequently, other genes such as GPDH must be used to be able to differentiate at the species level (Cannon et al. 2012; Manamgoda et al. 2014). Manamgoda et al. (2014) opined that the GPDH gene is the best single marker for species of Bipolaris. In order to differentiate SMYK1 from closely related species, its phylogenetic relationships with allied taxa were analyzed using concatenated sequences of ITS, GPDH, TEF-1 $\alpha$, and $L S U$, and it was determined to be $B$. oryzae.

B. oryzae has a broad host range (Manamgoda et al. 2014). Its hosts include not only gramineous and nongramineous crops but also some trees (Dela Paz et al. 2006; Manamgoda et al. 2014; Sanahuja et al. 2017). In this study, B. oryzae was shown to be the cause of shoot blight of Chinese fir, and was also determined to be pathogenic to rice and maize. In southern China, rotation of rice and C. lanceolata is usually used to improve the productivity of Chinese fir in nurseries and the quality of the seedlings (Qiu 2007). In Fujian, rice plants are sown in May to June and are harvested in November. In the following spring, from April to May, young Chinese fir seedlings are cultivated in the same field by sowing or cutting, and the seedlings are removed from the nurseries for afforestation in December. After rice harvesting, the remaining rice roots, stalks, and leaves are directly used as the matrix to cultivate Chinese fir. The Fujian location under study is part of the distribution area of rice brown spot disease caused by $B$. oryzae. To complicate matters, due to long-term artificial selection mainly based on the growth, only a few Chinese fir varieties or clones are used and, thus, they are most likely to be
A

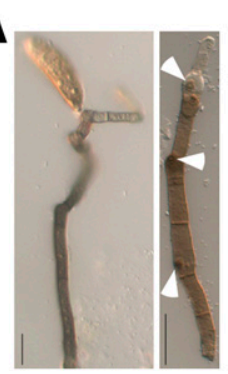

B

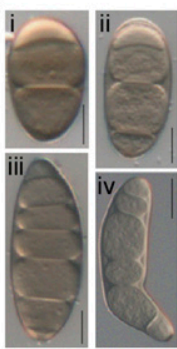

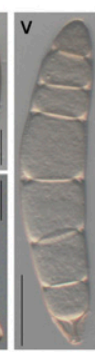
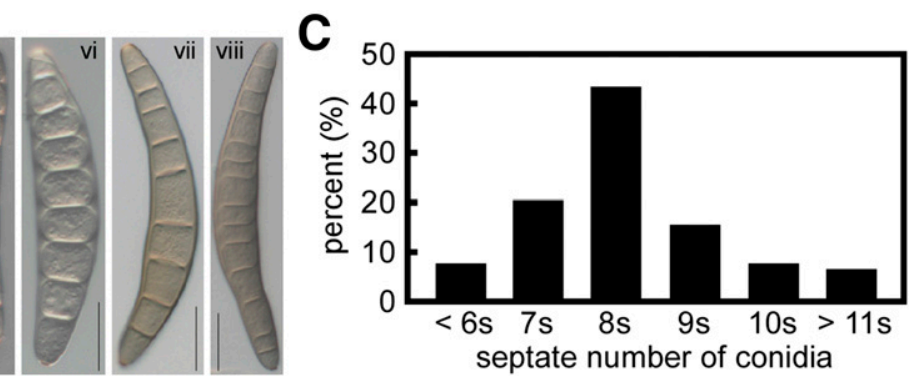

Fig. 5. Conidiophore and conidial morphological characteristics of SMYK1. A, Conidiophores with septations. Arrowheads indicate sporulation pores. B, Conidia: i to iii show straight conidia whereas iv to viii indicate curved conidia. C, Percentage of conidia with different septate numbers. Bars $=20 \mu \mathrm{m}$.

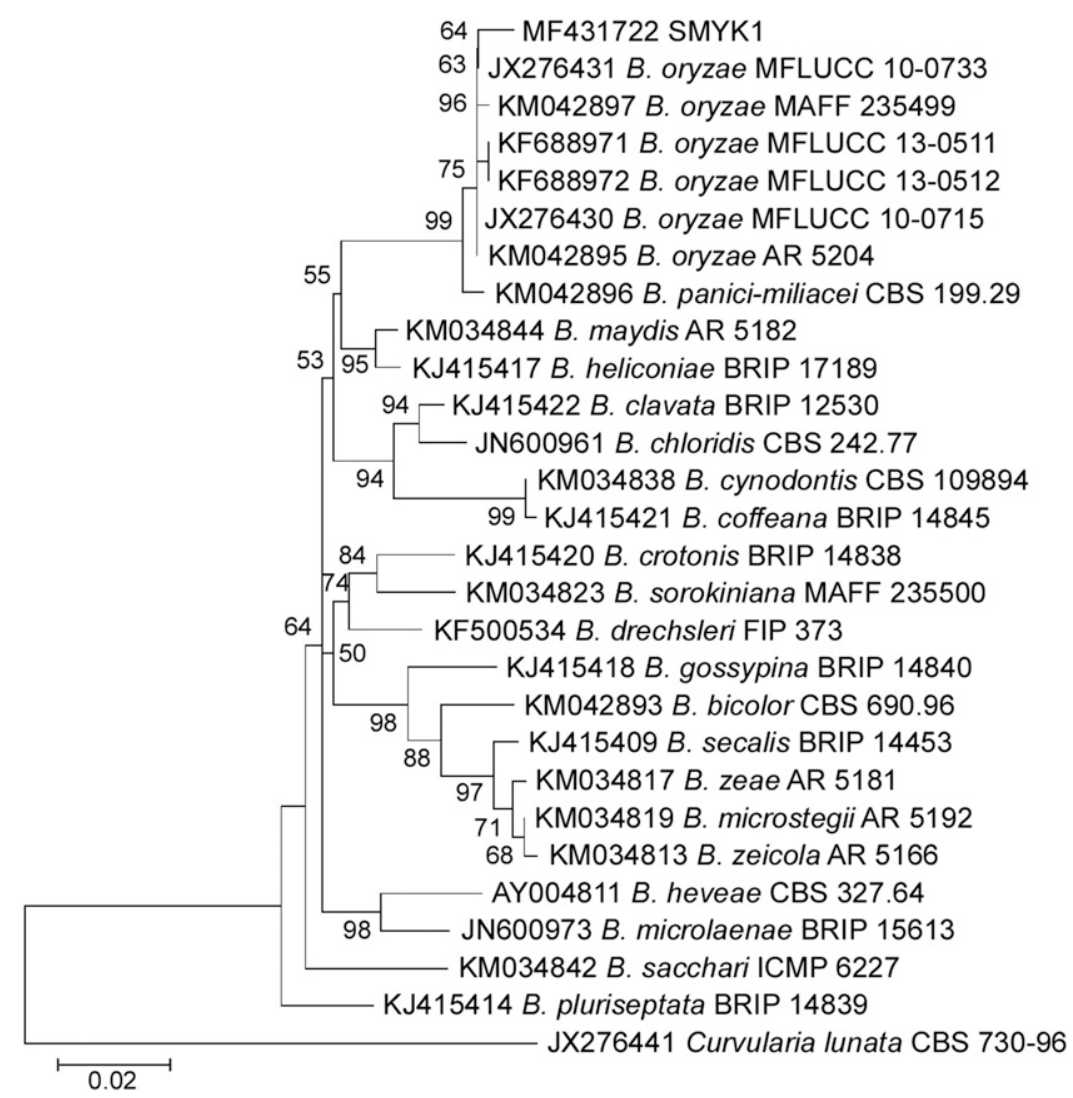

Fig. 6. Phylogenetic tree of SMYK1 with allied taxa calculated from the partial glyceraldehyde-3-phosphate dehydrogenase gene using neighbor-joining method. Bootstrap values $>50 \%$ (1,000 replications) are given at the nodes. Curvularia lunata CBS 730-96 is used as an outgroup. Bar $=0.02$ substitution per nucleotide position. 
vulnerable to the disease. These factors, and particularly crop rotation with rice and Chinese fir, substantially increase the risk of shoot blight on C. lanceolata. Another possibility is that crop rotation may favor the appearance of populations of the pathogen more virulent on both hosts. In conclusion, we can say with a great level of confidence that the gymnosperm Chinese fir is a new host for $B$. oryzae, which causes a shoot blight previously reported as being induced by $B$. sacchari. To our knowledge, this is the first time that $B$. oryzae is reported on a conifer species.

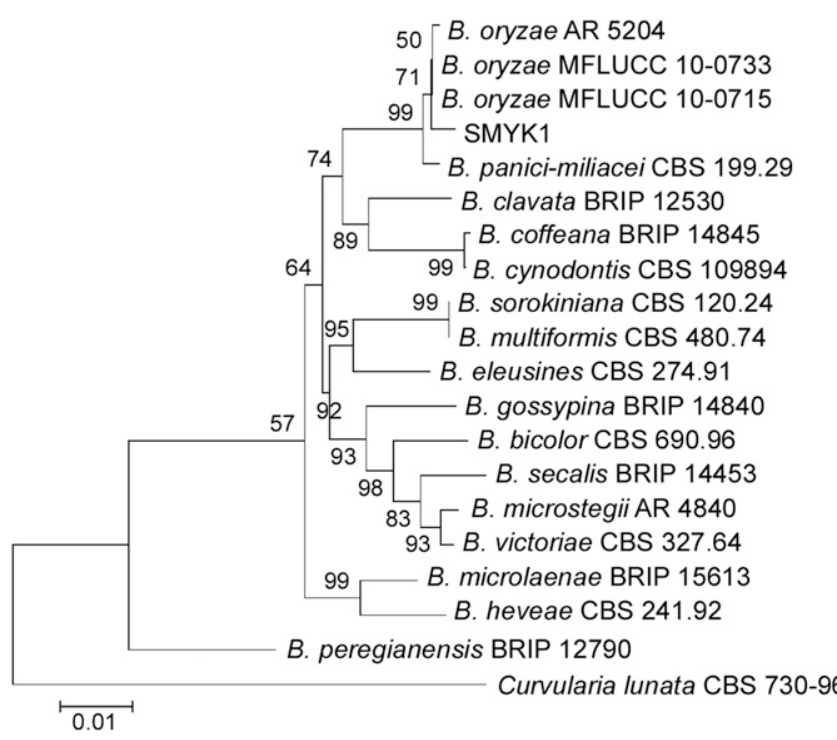

Fig. 7. Phylogenetic tree of SMYK1 with allied taxa calculated from the alignment of concatenated sequences of the internal transcribed spacer, partial glyceraldehyde-3phosphate dehydrogenase gene, partial translation elongation factor 1- $\alpha$ gene, and partial $28 \mathrm{~S}$ large subunit ribosomal RNA gene using the neighbor-joining method. Bootstrap values $>50 \%$ (1,000 replications) are given at the nodes. Curvularia lunata CBS 730-96 is used as an outgroup. Bar $=0.01$ substitution per nucleotide position.

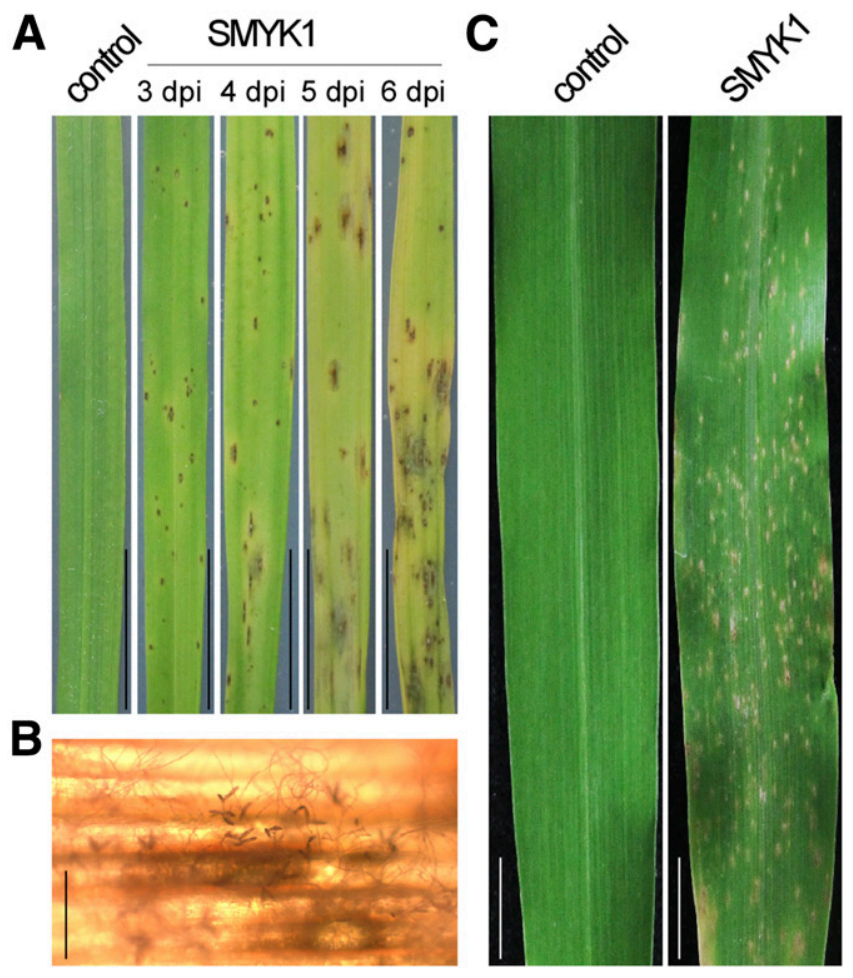

Fig. 8. Pathogenicity of SMYK1 on rice and maize leaves. A, Lesions on rice leaves at different days postinoculation (dpi). Bars $=1 \mathrm{~cm}$. B, Conidia formed on rice leave lesions ( $6 \mathrm{dpi}$ ). Bar $=0.5 \mathrm{~cm}$. C, Lesions on maize leaves (10 dpi). Bars $=1 \mathrm{~cm}$

\section{Acknowledgments}

This study was financially supported by the National Key R \& D Program of China (2017YFD0600102), the Fund of Independent Innovation of Agricultural Sciences of Jiangsu province (CX(16)1005), and the Priority Academic Program Development of Jiangsu Higher Education Institutions (PAPD).

\section{Literature Cited}

Berbee, M. L., Pirseyedi, M., and Hubbard, S. 1999. Cochliobolus phylogenetic and the origin of known, highly virulent pathogens, inferred from its and glyceraldehyde-3-phosphate dehydrogenase gene sequences. Mycologia 91: 964-977.

Brun, S., Madrid, H., van den Ende, B. G., Andersen, B., Marinach-Patrice, C., Mazier, D., and de Hoog, G. S. 2013. Multilocus phylogeny and MALDITOF analysis of the plant pathogenic species Alternaria dauci and relatives. Fungal Biol. 117:32-40.

Cai, L., Giraud, T., Zhang, N., Begerow, D., Cai, G., and Shivas, R. G. 2011. The evolution of species concepts and species recognition criteria in plant pathogenic fungi. Fungal Divers. 50:121-133.

Cannon, P. F., Damn, U., Johnston, P. R., and Weir, B. S. 2012. ColletotrichumCurrent status and future directions. Stud. Mycol. 73:181-213.

Cholil, A., and de Hoog, G. S. 1982. Variability in Drechslera oryzae. Trans. Br. Mycol. Soc. 79:491-496.

Damm, U., Mostert, L., Crous, P. W., and Fourie, P. H. 2008. Novel Phaeoacremonium species associated with necrotic wood of Prunus trees. Persoonia 20:87-102.

Dela Paz, M. A. G., Goodwin, P. H., Raymundo, A. K., Ardales, E. Y., and Vera Cruz, C. M. 2006. Phylogenetic analysis based on ITS sequences and conditions affecting the type of conidial germination of Bipolaris oryzae. Plant Pathol. 55:756-765.

Ellis, M. B. 1971. Page 608 in: Dematiaceous Hyphomycetes. Commonwealth Mycological Institute, Kew, England.

Huang, L., Li, Q., Zhang, Y., Li, D. W., and Ye, J. 2016. Colletotrichum gloeosporioides s.s. is a pathogen of leaf anthracnose on evergreen spindle tree (Euonymus japonicus). Plant Dis. 100:672-678.

Jatoi, G. H., Abro, M. A., Tariq, J. A., Memon, S., Mangi, N., Maitlo, S. A., Kerio, A., Hussain, S., and Mengal, A. 2016. Efficacy of selected fungicides on the linear colony growth of the Helminthosporium oryzae caused by brown spot disease of rice. Par. J. Biotechnol. 13:13-17.

Johannesson, H., and Stenlid, J. 1999. Molecular identification of wood-221 inhabiting fungi in an unmanaged Picea abies forest in Sweden. For. Ecol. Manage. 115:203-211.

Kumar, S., Stecher, G., and Tamura, K. 2016. MEGA7: Molecular evolutionary genetics analysis version 7.0 for bigger datasets. Mol. Biol. Evol. 33:1870-1874.

Lan, X., Dong, L., Huang, K., Chen, D., Li, D., and Mo, L. 2015. Main species and prevention research on diseases and pests of Cunninghamia lanceolata. Guangxi For. Sci. 44:162-167.

Li, M., He, J., Ding, L., Kang, J., Zhang, Q., and Zheng, Q. 2007. Single spore strains without producing fruit body isolated from Cordyceps militaris and their RAPD analysis. Southwest China. J. Agric. Sci. 20:547-550.

Malan, A. P., Knoetze, R., and Moore, S. D. 2011. Isolation and identification of entomopathogenic nematodes from citrus orchards in South Africa and their biocontrol potential against false codling moth. J. Invertebr. Pathol. 108: 115-125.

Manamgoda, D. S., Cai, L., Bahkali, A. H., Chukeatirote, E., and Hyde, K. D. 2011 Cochliobolus: An overview and current status of species. Fungal Divers. 51: $3-42$

Manamgoda, D. S., Cai, L., McKenzie, E. H. C., Crous, P. W., Madrid, H., Chukeatirote, E., Shivas, R. G., Tan, Y. P., and Hyde, K. D. 2012. A phylogenetic and taxonomic re-evaluation of the Bipolaris-Cochliobolus-Curvularia complex. Fungal Divers. $56: 131-144$

Manamgoda, D. S., Rossman, A. Y., Castlebury, L. A., Crous, P. W., Madrid, H., Chukeatirote, E., and Hyde, K. D. 2014. The genus Bipolaris. Stud. Mycol. 79: 221-288.

Qiu, G. 2007. A study on the impact of rotation and succession planting on seedling growth and soil fertility in the forestry nursery. J. Fujian For. Sci. Technol. 34:109-111, 118.

Sanahuja, G., Lopez, P., Chase, A. R., and Palmateer, A. J. 2017. First report of Bipolaris oryzae causing leaf spot on Strelitzia nicolai in Florida. Plant Dis. 101:384.

Schoch, C. L., Crous, P. W., Groenewald, J. Z., Boehm, E. W. A., Burgess, T. I., de Gruyter, J., de Hoog, G. S., Dixon, L. J., Grube, M., Gueidan, C., Harada, Y., Hatakeyama, S., Hirayama, K., Hosoya, T., Huhndorf, S. M., Hyde, K. D., Jones, E. B. G., Kohlmeyer, J., Kruys, A., Li, Y. M., Lücking, R., Lumbsch, H. T., Marvanová, L., Mbatchou, J. S., McVay, A. H., Miller, A. N., Mugambi, G. K., Muggia, L., Nelsen, M. P., Nelson, P., Owensby, C. A., Phillips, A. J. L., Phongpaichit, S., Pointing, S. B., Pujade-Renaud, V., Raja, H. A., Rivas Plata, E., Robbertse, B., Ruibal, C., Sakayaroj, J., Sano, T., Selbmann, L., Shearer, C. A., Shirouzu, T., Slippers, B., Suetrong, S., Tanaka, K., Volkmann-Kohlmeyer, B., Wingfield, M. J., Wood, A. R., Woudenberg, J. H. C., Yonezawa, H., Zhang, Y., and Spatafora, J. W. 2009. A class-wide phylogenetic assessment of Dothideomycetes. Stud. Mycol. 64:1-15.

Schoch, C. L., Seifert, K. A., Huhndorf, S., Robet, V., Spouge, J. L., Levesque, C. A., Chen, W., Bolchacova, E., Voigt, K., and Crous, P. W. 2012. Nuclear ribosomal internal transcribed spacer (ITS) region as a universal DNA barcode marker for Fungi. Proc. Natl. Acad. Sci. USA 109:6241-6246. 
Shi, J., Zhen, Y., and Zheng, R. 2010. Proteome profiling of early seed development in Cunninghamia lanceolata (Lamb.) Hook. J. Exp. Bot. 61: 2367-2381.

Sivanesan, A. 1987. Graminicolous Species of Bipolaris, Curvularia, Drechslera, Exserohilum and Their Teleomorphs. Mycological Papers, number 158. CAB International Mycological Institute, Wallingford, Oxon, UK.

Subramanian, C. V., and Bhat, V. R. 1978. Taxonomy of Drechslera oryzae (Breda de Haan) Subramanian \& Jain. A reappraisal. Pages 136-148 in: Proc. Int. Symp. Taxon. Fungi, 1973

Thompson, J. D., Higgins, D. G., and Gibson, T. J. 1994. CLUSTAL W: Improving the sensitivity of progressive multiple sequence alignment through sequence weighting, position-specific gap penalties and weight matrix choice. Nucleic Acids Res. 22:4673-4680.

Verma, R. P. S., Singh, D. P., and Sarkar, B. 2002. Resistance to leaf spot (Bipolaris sorokiniana (Sacc.) Shoemaker) and net blotch (Helminthosporium teres Sacc.) in barley. Indian J. Plant. Genet. Resour. 15:17-18.
Wang, J., Cen, B., Jiang, Z., Peng, S., Tong, Z., and Li, G. 1995. Identification of the pathogen which causes Chinese fir shoot blight. Huahan Nongye Daxue Xuebao [J. South China Agric. Univ.] 14:47-49.

Weir, B. S., Johnston, P. R., and Damn, U. 2012. The Colletotrichum gloeosporioides species complex. Stud. Mycol. 73:115-180.

White, T. J., Bruns, T., Lee, S., and Taylor, J. W. 1990. Amplification and direct sequencing of fungal ribosomal RNA genes for phylogenetics. Pages 315-322 in: PCR Protocols: A Guide to Methods and Applications. M. A. Innis, D. H. Gelfand, J. J. Sninsky, and T. J. White, eds. Academic Press, New York.

Zheng, W., Chen, J., Hao, Z., and Shi, J. 2016. Comparative analysis of the chloroplast genomic information of Cunninghamia lanceolata (Lamb.) Hook with sibling species from the Genera Cryptomeria D. Don, Taiwania Hayata, and Calocedrus Kurz. Int. J. Mol. Sci. 17:1084.

Zhou, Y., Li, M., Zhao, F., Zha, H., Yang, L., Lu, Y., Wang, G., Shi, J., and Chen, J. 2016. Floral nectary morphology and proteomic analysis of nectar of Liriodendron tulipifera Linn. Front. Plant Sci. 7:826. 